\title{
Entre lo global y lo local Notas históricas y algunos retos de los estudios sobre los medios de comunicación de masas
}

Francisco J. Ferróndiz

\section{Introducción}

En las últimas décadas del siglo $\mathrm{XX}$, el mundo está sufriendo transformaciones de larguísimo alcance que están convirtiendo en obsoletos, a marchas forzadas, nuestros instrumentos de análisis y nuestros marcos de interpretación de los fenómenos económicos, sociales y culturales. El triunfo del llamado "capitalismo posfordista" (Harvey, 1989) y sus modos de "acumulación flexible" ha producido una tensión nueva entre los fenómenos de globalización y desterritorialización de los procesos productivos, y las diversas formas de experimentar lo local, lo cotidiano. Es precisamente esta contradicción uno de los aspectos más relevantes de los debates contemporáneos sobre modernidad y posmodemidad.

Obviamente, el universo de los medios de comunicación es uno de los lugares donde estas transformaciones se están dando a mayor velocidad, y algunas de las dimensiones de su impacto son todavía desconocidas, incluso inimaginables. La información se ha convertido en una de las mercancías más significativas -y en uno de los principales instrumentos de poder- de nuestra época. Según Castells, "las nuevas tecnologías de la información están transformando el modo en el que producimos, consumimos, organizamos, vivimos y morimos" (1989: 15). Los media, fundamentalmente la televisión, saturan nuestras vidas. En palabras de Fiske, "en una hora de televisión cada uno de nosotros probablemente experimenta más imágenes que cualquier miembro de una sociedad no industrial experimentaría en toda su vida. La diferencia cuantitativa es tal que se convierte en categórica; no sólo experimentamos más imágenes, sino que se produce en nuestras vidas una relación totalmente distinta entre las imágenes y el resto de las órdenes de la experiencia" (1991: 58). 
La llamada "revolución" (tanto tecnológica como institucional) en las formas en las que la información se produce, circula y se consume, se basa en procesos de proliferación, privatización, diversificación, comercialización, internacionalización y descentralización de los medios de comunicación y, muy fundamentalmente, de la televisión (Ang, 1996: 3). El estudio del impacto social de la producción y circulación de información en los medios de comunicación en el mundo contemporáneo exige, pues, un replanteamiento a fondo de las relaciones entre lo elitista (o hegemónico), lo masivo y lo popular, lo que implica a su vez una nueva forma de pensar las relaciones entre lo local y lo global. Con la industrialización y la llegada de los procesos de masificación de la información se produjo una fractura sin retorno en las formas que lo "cultural" y lo "político" adoptaban previamente. En el transcurso de este proceso de globalización de la producción, distribución y consumo de mensajes mediáticos, la cultura popular fue perdiendo su referencia única en lo local y se fue entrelazando con formas comerciales de lo masivo.

\section{Apuntes históricos}

Entonces, ¿cómo aproximamos a la nueva escala de los fenómenos mediáticos? En el presente trabajo, se propone un itinerario esquemático a través de las principales tendencias de los estudios de los medios de comiunicación desde su origen, para pasar a continuación a discutir algunas propuestas más recientes con mayor capacidad para asumir en su marco analítico las enormes transformaciones que están teniendo lugar en el campo, a un paso casi vertiginoso.

Las reflexiones más antiguas sobre los media datan de principios de siglo, y se han dado en llamar teoría de la "bala mágica", o modelo de la "jeringuilla hipodérmica" de los efectos de los media. Son éstos modelos teóricos donde los media tienen un papel netamente propagandístico. Se asume que las audiencias son pasivas y los mensajes mediáticos tienen un efecto determinante sobre ellas. Estas primeras aproximaciones se basaban, en líneas generales, en las siguientes premisas: los mensajes mediáticos son recibidos de manera uniforme por los miembros de una sociedad de masas determinada; dichos mensajes actúan como estímulos de la conducta individual; estos estímulos impulsan a las audiencias a comportarse de forma homogénea; los efectos de la comunicación de masas son poderosos, uniformes y directos (Lowery \& Defleur, 1988: 23-24).

Este "paradigma dominante" de los estudios sobre la comunicación masiva hasta los años 1970 se configuró como una subdisciplina de la sociología funcionalista norteamericana. Son por lo tanto teorías que priorizan el análisis de los efectos socialemente integradores de los media. En este contexto se produjeron innumerables estudios centrados en la valoración de los "efectos" y "usos" de los medios de comunicación (McQuail, 1983; Ang, 1996). Dentro de esta perspectiva se definieron cinco tipos de funciones de los media: a) la función de 
vigilancia (los media nos proporcionan un flujo continuo de información sobre el mundo); b) la función de otorgamiento de rango (la exposición a los media proporciona prestigio a individuos, organizaciones o movimientos sociales); c) la función de "aplicación forzosa de normas sociales" (el flujo público de normas sociales cierтa la distancia entre éstas y las actitudes privadas); d) la función de transmisión cultural (los media se han convertido en los máximos agentes de socialización del mundo contemporáneo); e) la función narcotizante (el mero exceso de información puede llevar a la trivialización de asuntos importantes).

La perspectiva que subyace en este tipo de investigaciones se basa en la premisa de que el comportamiento de las audiencias ha de valorarse en relación a su grado de "conformidad" o "inconformidad" con aquellos procesos sociales que eran considerados normativos. Esto produjo un interés especial por los efectos presuntamente "disfuncionales" que la televisión ejercía sobre audiencias "vulnerables" tales como minorías étnicas, mujeres, pobres y ancianos (Comstock, 1978). Estas aproximaciones funcionalistas, basadas en la presunta existencia de una "integridad cultural", han sido criticadas por su afán positivista y por su tendencia a adoptar el punto de vista de la propia sociedad mediática, y también de los "guardianes oficiales de la sociedad y la moral pública" (McQuail, 1983).

El primer intento de alcance internacional por teorizar la fimensión real de estos cambios tan radicales, tal y como afectaban al balance entre lo elitista, lo masivo y lo popular en América Latina corrió, en la década de 1970, a cargo de autores como Pasquali (desde Venezuela), Wells (1972) y Dorfman y Mattelart (1975). En un marco teórico distinto del funcionalismo, aunque compartiendo algunas de sus premisas, estos investigadores utilizaron la tradición negativista que provenía de la Escuela de Francfort (sobre todo en los trabajos de Adorno [1991], Adomo y Horkheimer [1972] y Marcuse [1964] para articular un diagnóstico radicalmente pesimista de los medios de comunicación masivos, o medios de "engaño masivo", en palabras de Adorno y Horkheimer (1972). Para los seguidores de este enfoque político-económico que prioriza las relaciones de conflicto, los media son propiedad de las clases dominantes, que los usan como mecanismos al servicio de sus propios intereses. Los media, de este modo, juegan un papel trascendental en la difusión e imposición de ideologías. En este sentido, y mediante el análisis de los cómics de Disney, Dorfman y Mattelart (1975) elaboraron su versión de la teoría del "imperialismo cultural" occidental, para denunciar el potencial totalitario de los medios electrónicos. El costo de la "modernización" vehiculada por los medios de comunicación era la destrucción de las formas de autenticidad local.

En esta visión catastrófica, los media, controlados a voluntad por las multinacionales, no sólo eran un paraíso para la manipulación política, sino que además aniquilaban sistemáticamente otras formas de cultura o memoria colectiva alternativas. Dorfman y Mattelart pensaban que gracias a los medios de comuni- 
cación, la "ideología dominante" podía imponer su visión política mediante la "integración cultural". Se ha criticado con frecuencia a esta escuela de pensamiento el uso de un concepto de "cultura" desfasado por el propio impacto de los medios de comunicación que eran el foco de su análisis, donde ésta es una entidad orgánica y auto-contenida con fronteras fijas. Otra línea de crítica apunta que este tipo de aproximaciones dieron origen a la todavía influyente imagen de la "audiencia pasiva" y fácilmente manipulable.

Una variante de esta rama de estudios de conflicto se basa en el trabajo del filósofo marxista francés Louis Althusser (1971). Para Althusser, instituciones tales como los media, la educación, la religión o la familia, aunque son o pueden ser independientes del Estado, reproducen de hecho la ideología dominante. Althusser denominó a estas instituciones "aparatos ideológicos estatales", para distinguirlos de los "aparatos represivos", como la policía o el ejército, que emplean un tipo de poder más directo. Las ideologías construyen relaciones imaginarias que obscurecen la realidad de la explotación.

El impulso de un tipo de análisis culturalista crítico con los medios de comunicación, conocido como "estudios culturales", desde mediados de la década de 1970 , ha sido fundamental para la adecuación paulatina de los estudios sobre los fenómenos masivos a las nuevas circunstancias de la posmodernidad. Como disciplina académica, los "estudios culturales" nacieron con una vocación ecléctica e interdisciplinaria. Se basan en la premisa de que la "cultura" no es un objeto discreto con límites precisos, como pretendían los funcionalistas, sino que es un proceso social abierto, contradictorio, discontinuo, donde tiene lugar la producción, circulación y consumo de significación. Para esta escuela de pensamiento, lo cultural es un elemento fundamental de lo cotidiano, y los significados culturales sólo se pueden aprehender como un proceso dialéctico dentro de una estructura de dominación y resistencia.

Frente al paradigma funcionalista dominante, los "estudios culturales" se interesaban por los procesos históricos de significación y no por los tipos generales de comportamiento, por la cultura como proceso y no como causa. Asimismo, los "estudios culturales" se definían como una aproximación de naturaleza interpretativa en lugar de explicativa, basada en una metodología etnográfica (Ang, 1996). Se considera que el Centro de Estudios Culturales Contemporáneos de la Universidad de Birmingham fue el foco desde donde irradiaron los estudios culturales, de la mano de investigadores de la talla de Hall, Willis, Hoggart, Hebdige, Gilroy y Morley.

Stuart Hall marcó la pauta de comunicación en un famoso artículo llamado "codificar/descodificar" ["encoding/decoding"], donde se planteaba la compleja estructura de relaciones que se constituye entre la producción, distribución y consumo de mensajes (1980). Este influyente modelo de recepción de mensajes mediáticos abrió un espacio de reflexión sobre la forma en que las significacio- 
nes "preferidas" por los codificadores originales pueden ser desenfocadas en distinto grado por las audiencias. Es decir, los mensajes hegemónicos resuenan de forma diferente con los valores polisémicos de las distintas audiencias. Hall definía un esquema con tres posibles tipos de decodificación: la dominantehegemónica; la negociada; y la de oposición, en cuyo marco era posible la desestabilización del mensaje, que se reconstruía en un marco de interpretación alternativo (ibid.) El trabajo de Hall fue vital en el despegue de los "estudios de recepción", interesados en las interpretaciones y usos que las audiencias hacen de los textos y tecnologías mediáticos (Morley, 1980 y 1992; Hobson, 1982). En este contexto, "recepción" no es un concepto de vocación individual o psicológica, sino más bien cultural y política.

En sintonía con esta tendencia culturalista emanada de Birmingham, J. Franco elaboró en 1982 una respuesta consistente a las tesis del imperialismo cultural en relación al impacto de los medios de comunicación masivos en las sociedades latinoamericanas. De acuerdo con Franco, es necesario reevaluar la oposición entre lo popular y lo masivo fuera de un marco epistemológico radical, no exento de nostalgia, donde ambos se encuentran en permanente conflicto. Si ha de tomarse en serio el análisis que hace Gramsci (1971) del concepto de "hegemonía", que es siempre un proceso incompleto, ya no se puede seguir pensando que los mensajes codificados en los media responden a una única ideología dominante, homogénea y preprogramada, que logra imponerse inexorablemente sobre la sociedad. Para Franco, una forma más productiva de analizar estos procesos es concebir lo masivo y lo popular como un único campo donde se entrecruzan múltiples prácticas y se intercambia significación. Del mismo modo y con el mismo fin, proclama la importancia de llevar a cabo estudios sistemáticos de la recepción de los mensajes producidos en los medios de comunicación, para romper así la unidireccionalidad de los análisis producidos en el marco del "imperialismo cultural”, que presuponen una gran pasividad simbólica y política de los espectadores.

En el ámbito de los "estudios culturales", bajo la influencia de Hall, una buena parte de los estudios de recepción de mensajes mediáticos desembocó en la romantización de las audiencias, una tendencia cristalizada en el influyente trabajo de John Fiske (1987). Simultáneamente al desarrollo de esta tendencia, que enfatizaba de modo casi exclusivo el aspecto de "resistencia" a la hegemonía dominante que se producía en las audiencias, tomó cuerpo una "reacción populista", ante la inexorabilidad del poder elitista (Ang, 1996) que celebraba la vitalidad y la energía con la que aquellos que en principio estaban excluidos de las formas de poder institucional creaban un mundo significativo y autónomo mediante la manipulación crítica de las materias primas que les suministraba la propia cultura hegemónica. Fiske llegó a promulgar, virtualmente, la independencia de las audiencias en relación con los medios de comunicación en la lucha cultural que se produce en torno al significado y al tiempo libre. Al adoptar esta visión, el investigador se convierte en un seguidor incondicional de lo popular,

Entre lo global y lo local 
perdiendo así buena parte de su potencial capacidad crítica frente a la complejidad de los procesos mediáticos.

En este contexto, uno de los trabajos más influyentes en el estudio del impacto de los medios de comunicación en las sociedades latinoamericanas es el del investigador colombiano Jesús Martín Barbero (1987; 1993). En oposición a aquellas perspectivas que asumen que la recepción de mensajes se impone inexorablemente desde un medio determinado, o las que celebran las audiencias como agentes autónomos con capacidad casi infinita de subversión, Martín Barbero entiende los medios de comunicación como "mediaciones" o puntos de encuentro, de una gran complejidad. Frente a posiciones como la de Fiske, Martín Barbero enfatiza que lo popular y lo hegemónico no pueden considerarse como mutuamente extemos, sino que participan de la misma serie de relaciones. Martín Barbero, retomando el sentido procesual dado por Gramsci al concepto de "hegemonía", piensa que los fenómenos sociales deben entenderse estudiando la "densa textura de lo hegemónico y lo subalterno, el continuo entrelazamiento de la resistencia y la sumisión, de la oposición y la complicidad" (1988). Sólo mediante el análisis en profundidad de este complejo entrelazamiento, que no es una relación fija sino un proceso, puede superarse la inercia que ancla los estudios de las audiencias en oposiciones tan obsoletas como pasivo/activo, manipulativo/liberador, etc.

Los media son vehículos o mediaciones de momentos de masificación específicos, pero no son su origen. Para Martín Barbero, la constitución histórica de lo masivo no implica un proceso de degradación de la cultura popular, sino que más bien vinculó estos procesos culturales con el mercado, el Estado y la globalización. Y de este modo, permitió que lo popular entrara, para bien o para mal, en una forma de complicidad con el imaginario masivo. Es importante prestar atención a las características culturales del público receptor. Martín Barbero es partidario de investigar aquellos códigos de recepción y reconocimiento específicos que emergen de las distintas formas de memoria popular. La cultura masiva se convierte así, de alguna manera, en un desarrollo de ciertas potencialidades de lo popular. La recepción es siempre múltiple y contradictoria, y puede subvertir o reapropiar de distintas formas los mensajes originarios. Por ejemplo, Martín Barbero utiliza los trabajos de M. Bakhtin $(1981$; 1984) para desgranar el potencial radicalizador contenido en el tono emocional de los melodramas, que considera el gran espectáculo de lo popular.

En los últimos años, la propuesta del antropólogo argentino afincado en México, Néstor García Canclini (1989) ha tenido una gran influencia en la reconceptualización de las relaciones entre lo hegemónico, lo masivo y lo popular en el "posfordismo" (Harvey, 1989; Jameson, 1991). Basándose en el trabajo de Gramsci y Bordieu, García Canclini picnsa que el impacto del capitalismo (sobre todo en su modo más recicnte de "acumulación flexible") en el mercado simbólico global ha tenido como consecuencia la emergencia de lo que denomi- 
na "culturas hibridas". La modemización y la masificación han disuelto la dicotomía entre lo elitista y lo popular, y los antiguos esquemas de análisis ya no son válidos para aprehender la nueva complejidad de la producción, circulación y consumo de bienes culturales.

Para García Canclini, al estar cada país atravesado por múltiples lógicas de desarrollo tanto político como económico, lo popular ha de ser concebido no como un nicho definible y estable sino más bien como una multiplicidad de estrategias cambiantes que se constituye en lo fundamental mediante pastiches y montajes eclécticos. Esta hibridación de la producción cultural es el resultado de tres procesos, todos ellos causados por la globalización del capital y la llamada "revolución de la información": la fragmentación y mezcla de las colecciones que organizaban los denominados "sistemas culturales"; la desterritorialización de los procesos simbólicos; y la expansión de los géneros populares impuros de la mano de las tecnologías de masas. Así, para entender las formas contemporáneas de lo popular es necesario explorar los nuevos procesos de producción industrial, los nuevos procesos transnacionales de producción y circulación masiva de bienes (materiales y simbólicos), así como las nuevas formas de recepción y apropiación de mensajes. Para García Canclini, los conceptos de "poder" derivados del trabajo de Foucault ya no permiten contemplar lo popular como exclusivamente pasivo y subordinado, sino entretejido con distintas redes políticas.

\section{La tensión entre lo global y lo local: La Guerra del Golfo como fenóme- no televisivo}

Paralelamente a la expansión de los medios de comunicación masivos, lo que se está globalizando no son tanto los contenidos culturales concretos como los parámetros y la infraestructura que denominan la existencia de las culturas locales. Así, la llamada "cultura global" no debe ser concebida como un proceso de homogeneización irreversible, como pretendían los estudios de la escuela del "imperialismo cultural". La globalización es también el proceso sistemático de desagregación y reinterpretación local de estos mensajes de naturaleza transnacional. El análisis de cualquier aspecto relacionado con los medios de comunicación debe basarse, pues, en el estudio de estas relaciones cambiantes entre la globalización, con sus poderosas formas de desterritorialización de lo cultural, y las nuevas articulaciones de lo local, donde (a la manera de García Canclini) la magnitud e influencia de estos procesos transnacionales y la circulación continua de bienes culturales hacen cada vez más difícil hablar de culturas o grupos sociales homogéneos o netamente delineados. Lo que la globalización está produciendo son nuevas formas de diferencia menos compartimentalizadas. Más interdependientes entre sí, pero al mismo tiempo distintivas.

Peters ha propuesto recientemente el concepto de "bifocalidad" para expresar -y tratar de entender- esta permanente tensión entre lo global y lo local

Entre lo global y lo local 
(1997). Para este autor, vivimos un conflicto entre nuestra experiencia fenomenológica y corpórea de lo local (1997). Para este autor, vivimos un conflicto entre nuestra experiencia fenomenológica y corpórea de lo local - fragmentaria por necesidad-y las representaciones panorámicas, totales, coherentes, extracorpóreas de la globalidad mediática —que denomina la "órbita de la información" (ibid.: 81). Así, mientras nos convertimos más y más en un "público virtual", la localidad se difumina como sede principal de la experiencia. Peters discute el ejemplo de la climatología para reflejar estas contradicciones. ¿Cómo compaginar la experiencia local del tiempo, es decir, los cielos azules, los vientos, las lluvias, los tomados y las inundaciones tal y como cualquier ciudadano los experimenta en su vida cotidiana, con las imágenes tecnológicas obtenidas por satélite de ese mismo clima, globalizado sobre mapas del planeta Tierra, y que son servidas diariamente por la televisión?

La Guerra del Golfo de 1991, una de las construcciones mediáticas (CNN) más impactantes de la última década, puede servirnos para hacer un breve recorrido por algunos de los debates que están teniendo lugar dentro del campo de los estudios de los media en relación a la naturaleza e impacto local de estas representaciones totalizadoras de circulación global a las que se refiere Peters. De hecho, según algunos autores, puede considerarse que la Guerra del Golfo es el caso más cercano a la ambición del presidente de la CNN, Ted Turner, de "transformar el mundo instantáneamente en una gran audiencia global" (Ang, 1996:150). Curiosamente, fue ésta una guerra mediática basada en la invisibilidad radical de la violencia real y la completa desaparición del "oponente" iraquí bajo una cascada de efectos visuales tecnológicos y una metanarrativa rica en metáforas de tipo médico y quirúrgico (Caldwell, 1995: 159; Feldman, 1994).

Autores como Wark (1994) consideran que fenómenos mediáticos —en este caso, fundamentalmente televisivo- de las dimensiones de la "Operación Tormenta del Desierto", suponen un ejemplo claro de lo que él ha denominado "geografías virtuales", donde la tendencia es que se implique todo el globo en un hecho mediático determinado, y donde cualquier espectador tenga la posibilidad de estar siempre "allí", en este caso, de "participar" a su manera en la dinámica de la guerra, incluso si es legitimándola con su interés. Sin embargo, críticos como Ang se muestran muy escépticos ante la posibilidad de que exista una audiencia global equiparable a una gran comunidad diaspórica que participe simultáneamente en "la retransmisión en vivo de la historia según sucede", como algunos sostienen que fue el caso de la Guerra del Golfo (1996). Para Ang, que basa sus conclusiones en un estudio de recepción que llevó a cabo con sus propios estudiantes en la Universidad de Amsterdam, siempre hay una resistencia local a "la colonización de nuestra atención e interés orquestada por los media globales": Así: "la realidad construida por los media no ha conseguido destruir la realidad social" (Ibíd.: 151). Del mismo modo, no hay que perder de vista la propia “posmodernización” de la televisión y otros medios —envueltos en procesos de 
diversificación y descentralización interna-, que impide que éstos sean discernibles analíticamente como unidades cohesionadas (lbíd.: 3). Así, según Ang, ni las audiencias son necesariamente comunidades virtuales al estilo de Wark, ni los media son necesariamente homogéneos.

Para Javier Echeverría lo importante es analizar la naturaleza de estos espectáculos televisivos en los ámbitos íntimos de la sociabilidad humana. La consolidación del "cosmopolitismo doméstico" producido por la expansión de los medios de comunicación de masas exige un replanteamiento radical de las relaciones entre lo global y lo local y entre lo público y lo privado. En relación a las nuevas "teleguerras", uno de los aspectos más relevantes sería la consolidación de un nuevo y crucial campo de batalla, el "frente doméstico", situado en la "telecasa", que se constituye así en un escenario privilegiado de la vida pública donde se pueden ganar o perder las guerras (1995: 168-175). La "teleopinión pública" se convierte en un poderoso ámbito de control social donde es tan posible ser avasallados por los "estrategas de la teleguerra" — tal y como ocurrió con la "Operación Tormenta del Desierto" - como resistir ante estos "montajes espectaculares" - como en el caso del conflicto de Somalia - articulando espacios dnmésticos de rechazo al conflicto (Ibídem).

Más allá de las dudas respecto a la naturaleza y posibles límites de la globalidad de estos procesos mediáticos, el filósofo francés Baudrillard ha cuestionado incluso la certeza de que existiera una "historia en vivo" en las representaciones que los televidentes consumieron ávidamente durante la guerra. En este sentido, basa su polémico análisis de este conflicto bélico en la premisa de que la simulación se ha convertido en el aspecto central de la vida social. Desde este punto de vista, la Guerra del Golfo no fue sino un simulacro televisivo, una representación hiperreal, un mundo de signos e imágenes generados en los media cuya conexión con la realidad no era directa o fácil dilucidar (1991). Los verdaderos campos de batalla, donde se produjo el sufrimiento y la muerte de miles de ciudadanos y soldados iraquíes, fueron reemplazados por la saturación mediática y el espectáculo tecnológico y aséptico de un armamento en acción presuntamente quirúrgica. De este modo, la guerra y otras formas de lo atroz se pudieron experimentar desde los cómodos sillones de las salas de estar como una atractiva forma de entretenimiento, como también han señalado Kleinman y Kleinman (1997). Para Baudrillard, la guerra en los medios no es, pues, más que una simulación. Si acaso hubo un tiempo en el que se podía decir que los medios proporcionan copias de la realidad, ahora lo que hacen es producir su propia realidad. En palabras de Caldwell, que se refiere tanto a la Guerra de Iraq como a los disturbios de Los Ángeles de 1992, "[ a los pocos minutos de estallar los conflictos] el trauma social y la rebelión ya se habían convertido en artificios [imágenes, superficies reflectantes, proyectiles voladores de texto-imagen]. La cara del "otro peligroso" se colapsó en "artefactos de lo conocido" (1995: 159). La propia estructura del lenguaje televisivo había devorado a los sucesos. 
Es indudable que queda aún mucho que investigar y discutir en torno a las implicaciones de lo masivo, lo popular y lo hegemónico; de la realidad y el simulacro; de la comodificación de la cultura; de la resistencia y del "imperialismo cultural"; de la complejidad de los procesos —a la postre - de producción, circulación y consumo de bienes mediáticos en las sociedades contemporáneas. El punto clave pareciera ser, como señala Peters, el estudio matizado de esta tensión bifocal entre artificios globales -aún más si tomamos el "realismo" como un estilo de representación convencional entre otros, como sugiere Nichols (1991: 165 y ss.) y reinterpretaciones y experiencias locales, más o menos dóciles o críticas. Es decir, nos queda profundizar en el estudio de toda la gama de estrabismos, miopías, astigmatismos, videncias, deslumbramientos, espejismos y cegueras recíprocas que constituyen, subvierten y regeneran esta bifocalidad creciente.

\section{Bibliografia}

Adorno, T. , 1991. The Culture Industry, Londres, Routledge.

___ \& Morkheimer, 1972, 'The Culture Industry: Enlightenment as Mass Deception', The Dialectics of Enlightenment, Nueva York, Herder \& Herder.

Althusser, L., 1971, Lenin and Philosophy and (Other Essays, New Left Books.

Ang, 1., 1996, Living Room Wars: Rethinking Media Audiences for a Postmodern World, Londres, Routledge.

Bakhtin. M., 1981, The Dialogic Imagination, M. Holquist, ed. C. Emerson \& M. Holquist trads. Austin, University of Texas Press.

__, 1984 , Rabelais and His World. Iswolsky Irad. Bloomington, Indiana University Press.

Baudrillard, J., 1991, 'The Reality Gulf', The Guardian, 11 enero: 25

Caldwell, J. T., 1995, Televisuality: Style, Crisis and Authority in American Television, New York, Columbia Universily Press.

Castells, M., 1989,m The Informational City, Oxford, Blackwell.

Comstock, G., et al., 1978, Television and Human Bchavior, Nueva York, Columbia University Press.

Dorfman, A. y A. Mattelart, 1975, How to Read Donald Duck: Imperialist Ideology in the Disney Comic, Nueva York, International General.

Echeverria, J., 1995, Cosmopolitas domésticos, Barcelona, Anagrama.

Feldman, A., 1994, 'On Cultural Anesthesia: From Desert Storm to Rodney King', American Ethnologist 21 (2): 402-418.

Fiske, J., 1987, Television Culture, Nueva York, Routledge.

-_ , 1991, 'Posmodernism and Culture'. En J. Curran \& M. Gurevitch (eds.), Mass Media and Society, Londres, Methuen.

Franco, J., 1982, 'What's in a name? Popular Culture Theories and Their Limitations', Studies in Latin American Popular Culture, 1: 5-14

Garcia Canclini, N., 1989, Culturas hibridas: estrategias para entrar y salir de la modernidad, México D.F., Grijalbo.

Gramsci, A., 1971, Selections from the Prison Notebooks, Londres, Lawrence \& Wishart. Hall, S., 1980, 'Encoding/decoding', En Hall, S.; Hobson, D. \& P. Willis (eds.), Culture, Media, Language, pp. 128-138. Londres, Hutchinson. 
Harvey, D., 1989, The Condition of Postmoderniry: An Enquiry into the Origins of Cultural Change, Oxford, Basil Blackwell.

Hobson, D., 1982, Crossroads: The Drama of Soap Opera, Londres, Methuen.

Jameson, F., 1991, Postmodernism, or the Cultural Logic of Late Capitalism, Londres, Verso.

Kleinman, A. \& J. Kleinman, 1997, 'The Appeal of Experience; The Dismay of Images. Cultual Appropiations of Suffering in Our Times'. En Kleinman, Das \& Lock (eds.), Social Suffering, pp. 1-23. Berkeley, University of California Press.

Lowery, A. \& M. de Fleur, 1988, Milestones in Mass Comunications Research, Londres, Longman.

Marcuse, H., 1964, One Dimensional Man, Londres, Routledge.

Martín Barbero, J. 1987, De los medios a las mediaciones: Comunicación, cultura y hegemonía, México, D.F., Ed. Calypso.

- - 1993, Communications. Culture and Hegemony, Londres, Sage.

Morley, D., 1980, The 'Nationwide' Audience, Londres, BFI.

- - 1992, Television, Audiences and Cultural Studies, Londres, Routledge.

Nichols, B., 1991, Representing Reality: Issues and Concepts in Documentary, Bloomington, Indiana University Press.

Peters, J. D., 1997, 'Seeing Bifocally: Media, Place, Culture'. En A. Gupta \& J. Ferguson (eds.), Culture, Power, Place: Explorations in Critical Anthropology,

Wark, M., 1997, Virtual Geographies: Living with Glohal Media Events, Bloomington, Indiana University Press.

Wells, A., 1972, Picture-Tube Imperialism? The Impact of US TV in Latin America, Nueva York, Orbis. 